Original Research Paper

\title{
The Step of Kouros
}

\author{
${ }^{1}$ Paul Nicholas Dimotakis and ${ }^{2}$ Panagiotis Papaspirou \\ ${ }^{1}$ Emer. Prof. of Nuclear Chemistry, Formerly Professor of Radiochemistry and Radiation Chemistry, University of Patras, \\ Patras, Greece \\ ${ }^{2}$ Department of Physics, Section of Astrophysics, Astronomy and Mechanics, National and Kapodistrian University of Athens, \\ Panepistimiopolis, GR 15783 Zographos, Athens, Greece
}

\author{
Article history \\ Received: 03-03-2015 \\ Revised: 11-05-2015 \\ Accepted: 11-05-2015 \\ Corresponding Author: \\ Panagiotis Papaspirou \\ Department of Physics, Section of \\ Astrophysics, Astronomy and \\ Mechanics, National and \\ Kapodistrian University of \\ Athens, Panepistimiopolis, GR \\ 15783 Zographos, Athens, Greece \\ Email: p.papaspirou973@gmail.com
}

\section{Introduction}

The "hellenopoietic" space (Dimotakis, 2006; 1999) comprises a specific, but also complex, a rich in content and structure, an abstract but also material, entity. This entity induces through the process of emergence the various fundamental and most basic memeplexes of the Hellenic civilization. These memeplexes propagate as solitonic structures (Zabusky and Porter, 2010) within the flow of Historical Time and through various Civilizations influenced by the Hellenistic and Alexandrian civilization. The hellenopoietic space can be understood as a synergy of the geosphere, of the biosphere and of the epiphenomenal noosphere of a concrete geographical area (Vernadsky et al., 2014). We attribute the neologism "hellenopoietic space" in order to define a space, both in its material extend, as well as in its abstract characteristics, which shapes and is shaped by, the Hellenic civilization.

The hellenopoietic space defines the generating form for the Hellenic Man (Borgeaud and Vernant, 2000). The hellenopoietic space structures, attributes meaning and constraints the Hellenic Worldview and the Hellenic
Zeitgeist. This space defines the hellenopoietic Order of Things, within a study about the properties of a connectionismic theory of the Hellenic civilization, seen as a cybernetic entity (Pinker and Mehler, 1988). We may regard the hellenopoietic space also as an abstract informational entity, where the totality of the forms and functions, the primal entities, the most fundamental elements of the Hellenic cultural noosphere are created and recreated, emerge and evolve. Matter, Energy and Information, all these most basic quantities transform according to the features of the hellenopoietic space.

Within contemporary Science, the role of information and its fundamental role within the scenery of Nature is being examined, departing from various angles of view (Chaitin, 2012; Gkigkitzis et al., 2013; Haranas and Gkigkitzis, 2013).

The geographical range of the hellenopoietic space stretches along the geographical borders of Greece and of Cyprus, including the Minor Asia shoreline. The deep and rich abundance of the biological species of this space defines another important characteristic of the hellenopoietic space. Also, the geological relief of the hellenopoietic space is extremely rich, it can be 
understood as a complex Voronoi decomposition of the geological background, which is fractal in nature. This decomposition defines a patchwork made by habitable and non-habitable places, as well as the complex archipelagos of the numerous islands of the Aegean Sea. The biological and climatologic nature of the hellenopoietic space can be described on the same ground, since it offers a wide variety of biological species, as well as their complex interactions between them and Man.

Within this natural scenery, with its beauty and richness, the hellenopoietic space gives birth to the concrete cultural characteristics of the Hellenic Man, the Man who creates, carries, evolves the Hellenic civilization. The small habitable geographical areas permit the birth of the Urban civilization, while at the same time it forbids the emergence of tremendous in extent Kingdoms, as it occurs for example in the cases of the Egyptian or the Babylonian civilization. We can imagine the core of the Hellenic civilization as an abstract network linking together Man, Nature and Society. The idiosyncratic features, the weak links of this network (Csermeli, 2006) attribute the emergent characteristics of this civilization and the generating factor of the fractal, almost random form of the geographical relief of the hellenopoietic space comprises such a dynamic factor for the birth of the Hellenic civilization. Also, the populations living within this natural environment are obligated to confront the fractal, chaotic complexity of their environment. These populations develop complex commercial societies, perfect the art of Sailing and are pushed into a vast colonization attempt. The hellenopoietic space induces both the appearance of the great maritime Hellenic civilization and the concrete, physiocratic in nature, rich in vastness and hierarchy, religion and philosophy. The hellenopoietic space governs the consecutive noospheric advancement of the Hellenic world-views, as the overall Zeitgeist of the Hellenic civilization emerges and evolves.

The Cycladic civilization, the Minoan civilization, the civilization of the City-states, at the epoch of the Ionian Renaissance, the age of the Presocratics, all of them are born within the matrix of the hellenopoietic space. The great exit en masse at the times of the Ionian Renaissance takes place at the period the Kouros breaks the sculptural stillness of the statues depicting the human body. A whole civilization and makes its first decisive step, into new geographical spaces and into novel noospheric Toposes. We can name this Step of Kouros as the Ionian Step. The Ionian Step is a Zeitgeist which conquers various noospheric accomplishments, it generatesvarious forms and functions in all the main aspects of a civilization. At the same time, its inner kernel remains clear and untouched, while it provides the energetic interaction and influence by the great Civilizations surrounding the hellenopoietic space. These civilizations include the great Egyptian and Persian civilization.

The structure and the function of the Hellenic noosphere gives birth to memeplexes, defining its own memepool (Dawkins, 1989). These memeplexes propagate through History and through the Byzantine (Laiou, 1995; Theodossiou and Danezis, 2010), the Arabic and Islamic (Sidoli and Van Brummelen, 2005; Meri, 2005) and the European civilization (Burckhardt, 2007). These memeplexes include the birth of the genre of Tragedy, of Physical Philosophy, of Astronomy, of Mathematics and of Democracy, as well as the basis for Science. Here, we encounter the notion of the Empirical investigation, the notion of the Logical argument and of the Proof, the notion of the Theorem and the notion of the Axiom, the notion of Rhetorics and the notion of Logos (Schrödinger, 1996), all of them combined as a tight, synergetic structure. As we move and shift through the Historical Time and arrive at the dawn of the $21^{\text {st }}$ century, we recognize the fruits of the hellenopoietic space, as delivered to our Common Global Heritage (Danezis and Theodossiou, 2012a).

One key concept, among the many, of the structure of the hellenopoietic space can be understood as the concept of Polis, the City-state (Dimotakis, 2005). The social and cultural construct of Polis (Hansen, 2006) can be viewed as a complex adaptive system (Holland, 1999), an open dissipative structure (Nicolis and Rouvas-Nicolis, 2007), which induces special kinds of cultural complexity and the generation of unique memes and memeplexes.

The uniqueness of the structure and the social and cultural relationships (Haken, 2008) among the social agents of the Polis, its Citizens, induces special and unique noospheric Toposes (Lefebvre, 1992), cybernetic (Wiener, 1965) spatiotemporal entities of a special character. We can never imagine the birth of Mathematics and of Philosophy, as well as of Science, both as a practice and as a theoretical activity, outside of the geographical, social and cultural borders of Polis. Polis induces a civilization based on the power of Logos, of the persuasive speech and most of all, of the social ability of the agents of the Polis to carry their freedom of speech beyond the ivory walls of the palaces of the Monarchs or beyond the walls of the houses of the rich and of the powerful.

As we mentioned above, within the overall complex cybernetic system (Turchin, 1977) of Polis, due to the properties of its internal nature, due to the special interactions (Csermeli, 2006) among its citizens, due to the special size of its population and due to the special kind of relationships between the Polis and its surroundings, novel pylons for our Common Global 
Heritage are born and cultivated. The presence of the Person dominates the civilization produced within Polis, the Citizen of Polis arises as a social and at the same time, psychological entity, above the member of a society governed by the divine prominence of an overall powerful Monarch. Living within the walls of a typical Polis plays a decisive role, since it enables, at the same time, to a critical number of active social participants to take action in their everyday affairs, but also in their cultural activities.

Among these, we understand the birth of Dialectics, that is the persuasive speech being built upon Argument and the birth of Mathematics, both based upon the concept of a Truth which can be demonstrated, a Truth which can be shown, a Truth which can be examined by everyone.

Polis gives birth to memetic structures (Moritz, 1995) which interact, but also induce, continuous cultural transitions and noospheric shifts within the Hellenic noosphere, passing from epochs of Chaos and Disorder to epochs of Order and cultural production (Dimotakis, 1999; 2006). These emergent memeplexes remain active within their solitonic existence, shape the perception of Reality, govern the relationships between Man, Nature and the Divine. These memetic structures shall also be used as building elements for all the forthcoming great Utopias produced by the great Civilizations which shall follow the Hellenistic and Alexandrian era. Here, the efforts of the Human being, of Man, of the Person, of the Citizen of Polis for knowing Nature, the Divine and Himself, are combined. The Selfknowledge of Man plays a central and decisive role within all the attempts embraced by the hellenopoietic space, while it acquires a form with concrete, distinct characteristics, of a most idiosyncratic nature, if compared to the other great civilizations.

The architectural counterparts of these great achievements (Salingaros, 2007) include the place of the Boule (parliament), of the Gymnasium, of the Theater, of the building used for the purposes of a Philosophic school, as well as of the Library, which especially appears at the begin of the Hellenistic era (Casson, 2002; El-Abbadi, 1992). The need and the necessity of certain architectural types of buildings, as well as of styles, rest upon the World-view and the Zeitgeist of the noospheric component of the hellenopoietic space. These architectural types define concrete material, but also abstract, they serve a special and urgent social meaning, a social function and a purpose which carries at the same time the religious, the philosophical, the scientific, the artistic, the technological achievements of the hellenopoietic space.

The hellenopoietic space induces the emergence of concrete Toposes, of spatial and temporal Structures, of buildings and of great ideas, providing their unique blueprint. These Toposes serve the actions and the Selfknowledge of the Hellenic Man. We can give the following basic example: The place of the Boule within Polis marks the appearance and the function of another great offspring of the hellenopoietic space, the notion of Democracy (Oben and Hedrick, 1996).

The Step of Kouros, the Ionian Step, symbolizes this great leap into the future. This gigantic leap is both social and cultural, material and noospheric and emerges naturally within the Topos of the hellenopoietic space and of the social environment of Polis, in particular. The step of Kouros, the Ionian Step, marks the "Plus Ultra" (Farrington, 1966) of a whole civilization. The enterprise of the Hellenic civilization towards the geographical terrae incognitae and the novel products, forms, meanings and functions of the noospheric Toposes (Mitani and Pessa, 2002), shall become one of the major attempts within our Common Global Heritage (Danezis and Theodossiou, 2012b).

\section{The Birth of Logos}

As a first step of the Hellenic Civilization we may regard the birth of Logos (Kirk et al., 1983) and the subsequent birth of Dialectics (Vlastos and Graham, 1995). Already, from the Orphic Hymns (Sideri, 2005; 2007), we encounter the concept of the Natural Law, which governs the celestial phenomena (AIC, 2014). Also, within the Homeric Texts (Nagy, 2012), the mentioned kings are not depicted as supreme rulers, as living beings placed between the men and the Gods. The Homeric Kings are described as purely human beings, which are governed by the will of the Gods, but also by their own passions. They do not decide according to the will of one Ruler, but according to the decision taken within the presence of a council of Kings or Monarchs. The presence of a robust, theoretical and practical framework of the science of Astronomy, a discrete Hellenic Cosmology, as it arises from the vast corpus of the Orphic Hymns (AIC, 2014) is combined with the voyages of Ulysses, voyages in unknown lands and Civilizations. Ulysses, a most important King and the main person in the Odyssey, suffers as a Man, being cursed by the will of the Gods, not as a Super-human being.

This critical qualitative kind, this critical, qualitative and quantitative value of social complexity, is of most importance. As we have mentioned, the degree and the nature of this social and cultural complexity permits the upheaval of the special, fundamental entities within the hellenopoietic space. One such example is the example of the Polis. The critical features of the Polis allow to the members of the aristocracy, or to the members of the middle class, or to the memebers of the working class and of the lower class, successively and as we proceed within 
historical time, to gain political control through their rights of free speech, through the right of exercising their Logos. Such characteristics also appear, in their infancy, in the Cycladic civilization (Marangou, 1991), the Minoan civilization (Papadopoulos, 2005) and the Mycenaean civilization (Chadwick, 1976), while they are totally absent in the great Civilizations being in close encounter with the Hellenic, for example the Persian, the Egyptian and the Phoenician Civilization.

This basic social action of the particular agent of the social structure of Polis, the Citizen (Csermeli, 2006) allows the appearance of a positive feedback loop, which enacts on the growth of Speech, accompanied with complex developments of Argument and Counterargument. This defines a most crucial feature of the homesteading of the complex cybernetic system of Polis. This Meta-systemic cultural transition produces the Language games of Dialectics, of Reason, of Logic, combined with an unsurpassed freedom in the examination of the Human Nature and Fate, as for example within the genre of Tragedy, or within the poetic texts of various Presocratic Philosophers.

We regard that these fundamental memeplexes, this Paradigmatic form of special kinds of Language games (Wittgenstein et al., 2010), serves as the canvas for the weaving of Philosophy, of Astronomy, of Science, in its wider sense and concept (Schrödinger, 1996). The Language games of the Scientific methodologies and the Scientific conceptual attitude towards physical reality are naturally combined with the Tragic Heroes, all of them acquiring their presence and meaning within the hellenopoietic space (von Schlegel et al., 1889).

\section{The Birth of Mathematics and of Science}

As a decisive Step of Kouros, a decisive Ionian Step, we can regard the birth of Mathematics (Filli, 2010; 2008). Mathematics arises from the depths of the hellenopoietic space, in order to describe, but also to impose Order and Beauty to the totality of the natural phenomena through the canonistic principles of Symmetry and Harmony (Papathanassiou, 1991).

We cannot conceive the birth of Mathematics without the additional study of the memeplexes and the, evolving and transforming in Historical time, memepool of the hellenopoietic space. Within the memepool of the hellenopoietic space the appearance of Mathematics arises in grandeur. The hellenopoietic memepool allows the free combinations and variants of its contents, gathered by the flow of Historical time and practice and by the accumulating knowledge gathered by the everyday social practice. Older forms are handled from anew, while novel elements come into being, by the mechanisms of Emergence, which rule the hellenopoietic space and at the same time enable its homeostasis, being valuable for its function and for its inner and outer, informational evolution.

The Orphic poet, who speaks with admiration about the existence of the Astrothetic Law, passes on the torch to the Presocratic philosophers (Sideri, 2005; 2007). Among this Hellenic tradition, the Pythagoreans attribute meaning to Mathematical rules governing Nature and Man and cultivate with furry the novel cultural and noopsheric branch of Mathematics, of Geometry and of Number theory. These rules govern an "organicismal" aspect of Cosmos, with all of its hierarchical levels of existence interacting strongly, thus giving birth to the little sister of Astronomy, Astrology (Papathanassiou, 2007).

Within the Hellenopoietic space archetypal Semiotic and Symbolic structures make they first appearance, while they continue to interact and fertilize the noopsheric achievements of many other civilizations, for example the scientific attitude towards matter and spirit, towards the theoretical taming of everyday reality (Gavroglou, 2004). Within the Hellenopoietic space, the tryptich composed of the notions of Man, Nature and the Divine, is actually combined with the Mathematical description of the ordered Universe, the Cosmos. The physical reality is bestowed with a strict aesthetic family of Meanings and Values. Additionally, the scientific branch of Astronomy and the foundation of many basic scientific disciplines, covered under the umbrella term of Physical Philosophy, shall propagate across spatial and temporal boundaries, all of them being born within the hellenopoietic space. Here, we can mention the fact that the appearance of Science, as well as the totality of the scientific and philosophical schools can be regarded as a complex socio-cultural phenomenon, taking place within a concrete sociocultural environment, within a concrete World-view and Zeitgeist (Arabatzis, 2005).

Within the appearance of the scientific thought and endeavor we have to stress the tremendous importance of the construction of the Mechanical universes, with prominent among them the example of the Antikythera Mechanism (Moussas, 2010; 2012; 2009). The construction of the first Cybernetic mechanisms and of the first complicated mechanical, hydraulic and pneumatic Automata, especially during the epoch of the Hellenistic and Alexandrian era, marks another gigantic cultural leap, another Step of Kouros. This can be studied not only within the context of the history and philosophy of Technology, but also within the context of 
a tremendous noospheric achievement (Wiener, 1965), whose roots can be found within the generating functions of the hellenopoietic space (Schmidt, 1899).

Also, the birth and the elaboration of the Heliocentric Astronomical and Cosmological Paradigm (Heath, 2004) can be found within a deep river of scientific tradition, beginning with the Pythagorean doctrines (Burkert, 1972) and ending at the epoch of its revival, through the work of Nicolaus Copernicus (Kuhn, 1992). We may regard the solitonic noospheric structures, for example the notion of Heliocentric, or the notion of the Automaton and the Computing Machine, or of the social system of Democracy, as major fruits offered by the hellenopoietic space, which now belong to our Common History and to our Common Global Heritage. We believe in the need of a thorough further investigation of the notion and the function of the hellenopoietic space, as well as for the main ideas presented in our discussion.

\section{Acknowledgement}

The authors would like to credit their acknowledgements to Konstantinos Karamanos, postdoctoral Researcher of the Complex Systems and Application Group, of the National Centre of Scientific Sciences, Demokritos, Athens, Greece, for various valuable discussions and comments.

\section{Author's Contributions}

Paul N. Dimotakis: Responsibility of introducing, analyzing and synthesizing the main idea of the emergence, the role and the function of the Hellenopoietic space.

Panagiotis Papaspirou: Provided background knowledge.

\section{Ethics}

This article is original and contains unpublished material. The corresponding author confirms that all of the other authors have read and approved the manuscript and no ethical issues involved.

\section{References}

AIC, 2014. Honorary volume for the astronomer constantinos chasapis-in Memoriam. Academy of Institutions and Cultures.

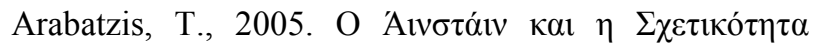
(Einstein and Relativity). 1st Edn., Crete University Press, Greek, ISBN-10: 960524215X.

Borgeaud, P. and J.P. Vernant, 2000. L Homme Grec. 1st Edn., Seuil, ISBN-10: 202038969X, pp: 433.
Burckhardt, J., 2007. The Civilization of the Renaissance in Italy. 1st Edn., BiblioPazaar, ISBN-10: 1426400934.

Burkert, W., 1972. Lore and Science in Ancient Pythagoreanism. 1st Edn., Harvard University Press, ISBN-10: 0674539184, pp: 535.

Casson, L., 2002. Libraries in the Ancient World. 1st Edn., Yale University Press, New Haven, ISBN-10: 0300088094, pp: 177.

Chadwick, J., 1976. The Mycenaean World. 1st Edn., Cambridge University Press, Cambridge, ISBN-10: 0521290376, pp: 201.

Chaitin, G.J., 2012. Proving Darwin: Making Biology Mathematical. 1st Edn., Pantheon, New York, ISBN-10: 0375423141, pp: 123.

Gkigkitzis, I., I. Haranas and S. Kirk, 2013. Number of information and its relation to the cosmological constant resulting from landauer's principle. Astrophys. Space Sci., 348: 553-557. DOI: $10.1007 / \mathrm{s} 10509-013-1581-4$

Csermeli, P., 2006. Weak Links: The Universal Key to the Stability of Networks and Complex Systems. 1st Edn., Springer, ISBN-10: 3540311513, pp: 410.

Danezis, E. and E. Theodossiou, 2012a. 'E $\tau \sigma \iota$ B $\lambda \dot{\varepsilon} \pi \omega$

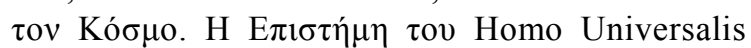
(My Own View at the World. The Science of Homo Universalis), in Greek. 1st Edn., Diavlos, ISBN-10: 9789605312930.

Danezis, E. and E. Theodossiou, 2012b. To $\Sigma v ́ \mu \pi \alpha v \pi o v$ А $\gamma \alpha ́ \pi \eta \sigma \alpha$ (The Universe I Loved), in Greek. 1st Edn., Diavlos, ISBN-10: 9789605312886.

Dawkins, R., 1989. The Selfish Gene. 2nd Edn., Oxford University Press, New York, ISBN-10: 0192860925 , pp: 352.

Dimotakis, P.N., 2006. Chaos and the Greeks. Georgiades. 1st Edn., Athens, Greece, ISBN-10: 9603162736.

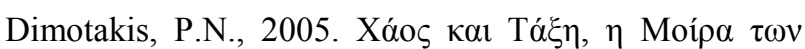

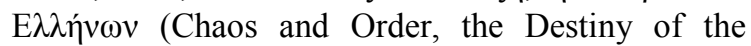
Greeks), in Greek. 1st Edn., Georgiades, Athens, Greece, ISBN-10: 9603162728.

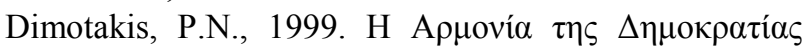
(The Harmony of Democracy), in Greek. 1st Edn., Georgiades, Athens, Greece, ISBN-10: 9609074707.

El-Abbadi, M., 1992. Life and Fate of the Ancient Library of Alexandria. 2nd Edn., UNESCO, ISBN-10: 9231026321, pp: 250.

Farrington, B., 1966. The Philosphy of Francis Bacon. 1 st Edn., University of Chicago Press, ISBN-10: 0226238857.

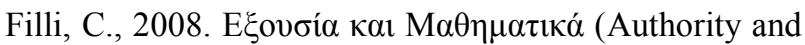
Mathematics), in Greek. 1st Edn., Papasotiriou, ISBN-10: 9789607182333. 


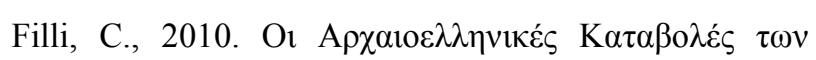

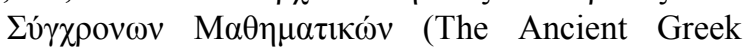
Roots of the Modern Mathematics), in Greek. 1st Edn., Papasotiriou, ISBN-10: 9789607182340.

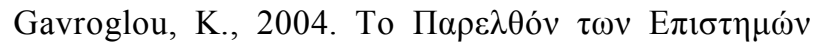
$\omega \varsigma$ I $\sigma \tau$ opí $\alpha$ (The Past of the Sciences as History), in Greek. 1st Edn., Crete University Press, ISBN-10: 9605241757.

Haken, H., 2008. Self-organization. Scholarpedia, 3: 1401-1401.

Hansen, M.G., 2006. Polis: An Introduction to the Ancient Greek City-State. 1st Edn., Oxford University Press, ISBN-10: 0199208506, pp: 246.

Haranas, I. and I. Gkigkitzis, 2013. Geometry of the Universe and its Relation to Entropy and Information. Adv. Astronomy, 2013: 809695-809697.

DOI: $10.1155 / 2013 / 809695$

Heath, T.L., 2004. Aristarchus of Samos: The Ancient Copernicus. 1st Edn., Dover Publications, Mineola, ISBN-10: 0486438864, pp: 425.

Holland, J.H., 1999. Emergence: From Chaos to Order. 1st Edn., Basic Books, ISBN-10: 0738201421, pp: 272.

Kirk, G.S., J.E. Raven and M. Shonfield, 1983. The Presocratic Philosophers: A Critical History with a Selection of Texts. 2nd Edn., Cambridge University Press, ISBN-10: 0521274559, pp: 511.

Kuhn, T., 1992. The Copernican Revolution: Planetary Astronomy in the Development of Western Thought. 1st Edn., Harvard University Press, ISBN-10: 0674171039, pp: 320

Laiou, A.E., 1995. Byzantium: A World Civilization. 1 st Edn., Harvard University Press, ISBN-10: 0884022153 .

Lefebvre, H., 1992. The Production of Space. 1st Edn., Wiley-Blackwell, ISBN-10: 0631181776, pp: 464.

Marangou, L.I., 1991. Cycladic Culture: Naxos in the 3rd Millennium B.C. 1st Edn., British Museum Press, ISBN-10: 071411295X, pp: 176.

Meri, J.W., 2005. Medieval Islamic Civilization: An Encyclopedia. 1st Edn., Routledge, New York, ISBN-10: 0415966906, pp: 155.

Mitani, G. and E. Pessa, 2002. Emergence in Complex, Cognitive, Social and Biological Systems. 1st Edn., Springer, ISBN-10: 146135224X, pp: 394.

Moritz, E., 1995. Metasystems, Memes and Cybernetic Immortality. In: The Quantum of Evolution. Toward a Theory of Metasystem Transitions, Heylighen, F., C. Joslyn and V. Turchin (Eds.), Gordon and Breach Science Publishers, New York, pp: 155-171.
Moussas, X., 2010. The Antikythera Mechanism. In: Adapting Historical Knowledge Production to the Classroom, Kokkotas, P.V., K.S. Malamitsa and A.A. Rizaki (Eds.), Sense Publishers, ISBN-10: 9789460913495, pp: 113-128.

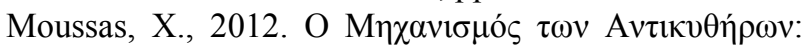

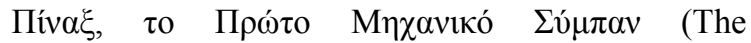
Antikythera Mechanism: Pinax, the First Mechanical Universe), in Greek. 1st Edn., EEF, Athens, Greece, ISBN-10: 9789609457187.

Moussas, X., 2009. The Antikythera Mechanism: The Oldest Mechanical Universe in its Scientific Milieu. Proceedings of the International Astronomical Union, (IAU' 09), pp: 135-148. DOI: $10.1017 / \mathrm{S} 1743921311002225$

Nagy, G., 2012. Homer The Preclassic. 1st Edn., University of California Press, ISBN-10: 0520256921, pp: 418.

Nicolis, G. and C., Rouvas-Nicolis, 2007. Complex Systems. Scholarpedia, 2: 1473-1473.

Oben, J. and C. Hedrick, 1996. Demokratia: A Conversation on Democracies, Ancient and Modern. 1st Edn., Princeton University Press, ISBN-10: 0691011087, pp: 496.

Papadopoulos, J.K., 2005. Inventing the Minoans: Archaeology, modernity and the quest for european identity. J. Mediterranean Archaeol., 18: 87-149. DOI: $10.1558 /$ jmea.2005.18.1.87

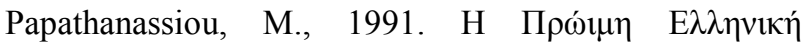

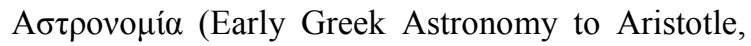
by Dicks, D.R.), Translation in Greek. 1st Edn., Daidalos I. Zacharopoulos, ISBN-10: 960227025X.

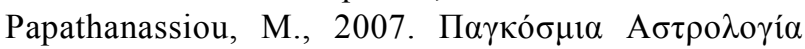
(World Astrology, by Marshall, P.), Translation in Greek. 1st Edn., Oceanida, ISBN-10: 9789604104567.

Pinker, S. and J. Mehler, 1988. Connections and Symbols. 1st Edn., MIT Press, Cambridge, ISBN-10: 0262660644, pp: 255.

Salingaros, N., 2007. A Theory of Architecture. 1st Edn., ISI Distributed Titles, ISBN-10: 3937954074 , pp: 278.

Schmidt, W., 1899. Herons von Alexandria Druckwerke und Automatentheater. 1st Edn., Teubner, Lipsiae, pp: 514.

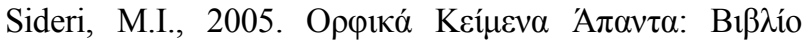
$\Delta \varepsilon \dot{\tau \varepsilon \rho о, ~ О \rho \varphi ı к ́ ~ \Theta \varepsilon о \lambda о \gamma i ́ \alpha ~(\Sigma v \lambda \lambda o \gamma \eta ́ ~ O t t o ~ K e r n) . ~}$

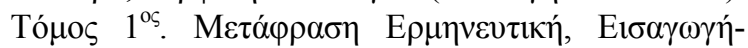
$\Sigma \chi o ́ \lambda 1 \alpha$. (Orphic Texts Collected: Second Book, Orphic Theology (Otto Kern Collection). Interpretative Translation, Introduction-Comments), in Greek. 1st Edn., Pyrinos Cosmos, Athens, Greece. 


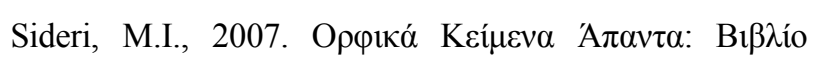

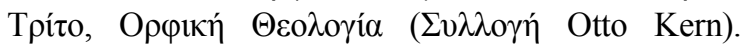

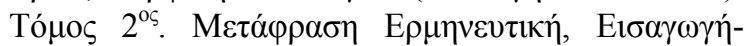
$\Sigma \chi o ́ \lambda ı \alpha$. (Orphic Texts Collected: Third Book, Orphic Theology (Otto Kern Collection). Interpretative Translation, Introduction-Comments), in Greek. 1st Edn., Pyrinos Cosmos, Athens, Greece.

Schrödinger, E., 1996. 'Nature and the Greeks' and 'Science and Humanism'. 1st Edn., Cambridge University Press, Cambridge, ISBN-10: 0521575508, pp: 172.

Sidoli, N. and G. Van Brummelen, 2014. From Alexandria, Through Baghdad. 1st Edn., Springer Berlin, Heidelberg, ISBN-13: 9783642367359.

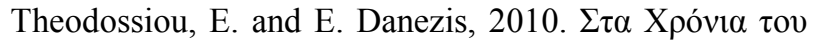

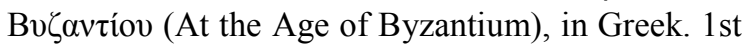
Edn., Diavlos, ISBN-10: 9789605312688.

Turchin, V.F., 1997. The Phenomenon of Science. 1st Edn., Columbia University Press, New York, ISBN-10: 0231039832, pp: 348.
Vernadsky, V.I., J.I. Ross and M.K. Rouillard, 2014. 150 Years of Vernadsky: The Noösphere (Volume 2). 1st Edn., Create Space Independent Publishing Platform, ISBN-10: 1500605395.

Vlastos, G. and D.W. Graham, 1995. Studies in Greek Philosophy, Vol. I: The Presocratics. 1st Edn., Princeton University Press, Princeton, ISBN-10: 0691019371.

von Schlegel, A.W., A.J.W. Morrison and J. Black, 1889. Lectures on Dramatic Art and Literature. 1st Edn., G. Bell \& Sons, pp: 535.

Wiener, N., 1965. Cybernetics, Second Edition: Or the Control and Communication in the Animal and the Machine. 2nd Edn., MIT Press, ISBN-10: 026273009X, pp: 212

Wittgenstein, L., P.M.S. Hacker and J. Schulte, 2010. Philosophical Investigations. 4th Edn., John Wiley and Sons, ISBN-10: 1444307975.

Zabusky, N.J. and M.A. Porter, 2010. Soliton. Scholarpedia, 5: 2068-2068. 